\title{
Model to manage and reduce crown-of-thorns starfish outbreaks
}

\author{
Elisabetta B. Morello ${ }^{1, *}$, Éva E. Plagányi ${ }^{1}$, Russell C. Babcock ${ }^{1}$, Hugh Sweatman ${ }^{2}$, \\ Richard Hillary ${ }^{3}$, André E. Punt ${ }^{3,4}$
}

${ }^{1}$ CSIRO Oceans \& Atmosphere, Ecosciences Precinct, 41 Boggo Rd, Dutton Park, QLD 4102, Australia

${ }^{2}$ Australian Institute of Marine Science, PMB 3, Townsville MC, QLD 4810, Australia

${ }^{3}$ CSIRO Oceans \& Atmosphere, Castray Esplanade, Hobart, TAS 7000, Australia

${ }^{4}$ School of Aquatic and Fishery Sciences, Box 355020, University of Washington, Seattle, WA 98195-5020, USA

\begin{abstract}
The crown-of-thorns starfish (COTS) Acanthaster planci is one of the largest causes of coral cover loss on Australia's Great Barrier Reef. Numerous trophic-mediated and anthropogenic-related hypotheses, singly or in combination, have been proposed to explain COTS outbreaks, but the evidence remains inconclusive. There is, however, an urgent need for effective control and mitigation strategies. We develop a model of intermediate complexity for ecosystem assessments to describe the trophic interactions between juvenile and adult COTS and 2 groups of coral (fast- and slow-growing corals). By fitting to available data, the impact of prey-switching behaviour by COTS and its effects on the system are quantified. Simulations are used to evaluate the effects of (1) predation by large fish on adult COTS, (2) predation by benthic invertebrates on juvenile COTS, and (3) manual removal of adult COTS. The results highlight the effectiveness of invertebrate predation at reducing juvenile COTS numbers and suggest that manual removal is unlikely to be an effective control method except on a small scale. Our model focuses on the importance of trophic interactions in COTS control and provides an initial platform for future work which foresees the estimation of the effects of key predators, no-take areas, anthropogenic nutrient enhancement, and reef connectivity in mediating the spatio-temporal heterogeneity of COTS outbreaks.
\end{abstract}

KEY WORDS: Acanthaster planci $\cdot$ COTS $\cdot$ Coral $\cdot$ Great Barrier Reef $\cdot$ Models of intermediate complexity $\cdot$ Predation $\cdot$ Trophodynamics Resale or republication not permitted without written consent of the publisher

\section{INTRODUCTION}

Crown-of-thorns starfish (COTS) Acanthaster planci (Linnaeus, 1758) feed primarily on scleractinian corals in the tropical and sub-tropical Indo-Pacific (De'ath \& Moran 1998a,b). Although generally rare $\left(\sim 1\right.$ COTS ha $\left.{ }^{-1}\right)$, their densities can undergo dramatic increases (termed outbreaks; reaching $>10000$ COTS $\mathrm{ha}^{-1}$ ); in some areas (e.g. the Great Barrier Reef [GBR], Australia), COTS are a leading cause of coral decline, along with cyclones and bleaching (Pratchett 2001, Osborne et al. 2011). Whether or not COTS outbreaks have always occurred in the GBR is uncertain, but outbreak frequency appears to have increased during the past $~ 50$ yr (Henderson \& Walbran 1992, Keesing et al. 1992). These outbreaks are indications of system instability and are likely due to particular biological traits of COTS and/or sudden changes in their environment (Pratchett 2001); the ability to control and manage COTS outbreaks relies on an understanding of both. Numerous studies have investigated the causes of these outbreaks, but no consensus has been reached, confounding certainty as to the effectiveness of alternative management actions.

The life history and biology of COTS are complicated. COTS are among the most fecund inverte- 
brates, with very high fertilisation rates and synchronous spawning, which peaks around January in the GBR (Babcock 1990, Babcock \& Mundy 1992, Benzie 1992). Fertilised eggs develop into planktotrophic larvae that settle after 11 to $22 \mathrm{~d}$ and metamorphose into juvenile COTS. Juveniles are initially slowgrowing and cryptic, feeding on crustose coralline algae for the first $\sim 6 \mathrm{mo}$, then switching to hard corals (Birkeland \& Lucas 1990, Zann et al. 1990, Keesing \& Halford 1992a). They start reproducing around 2 yr of age and can live to 7 or 8 yr (Birkeland \& Lucas 1990, De'ath \& Moran 1998a). COTS tend to be specialist feeders (e.g. on Acropora sp.) when coral is abundant, becoming more generalist (e.g. consuming massive corals such as Porites spp.) as food supply dwindles (Birkeland \& Lucas 1990). Although COTS are well-protected against predators (Birkeland \& Lucas 1990), several invertebrate and fish species have been reported to feed on healthy juvenile and adult COTS (e.g. benthic invertebrates, the giant triton Charonia tritonis, and some species of Lethrinidae, pufferfish, and triggerfish; Chesher 1969, Pearson \& Endean 1969, Ormond et al. 1973, Glynn 1982, Moran 1986, Birkeland \& Lucas 1990, Ormond et al. 1990).

An outbreak occurs when a COTS population consumes corals at a rate that is greater than the coral growth rate (Lourey et al. 2000), generally at densities $>10$ ind. ha ${ }^{-1}(>100$ COTS km²) (Birkeland \& Lucas 1990, Moran \& De'ath 1992, Keesing \& Lucas 1992). Three types of outbreaks can be distinguished: primary, secondary, and chronic (Moran 1986, Birkeland \& Lucas 1990). Primary outbreaks are those in which a small localised population of COTS abruptly increases by $>2$ orders of magnitude. Secondary outbreaks are generated by larvae spawned by primary outbreaks settling on reefs downstream. Their distribution in space and time is related to the hydrodynamics of the water masses (e.g. southwards in the mid-shelf and outer GBR) (Kenchington 1977, James et al. 1990). Secondary outbreaks occur in waves as larvae progress in a 'stepping-stone' pattern from reef to reef through the central GBR, and so appear in cycles (in the GBR, average frequency $=14.95 \mathrm{yr}$; Seymour \& Bradbury 1999), depending on coral abundance and recovery. Chronic situations describe the continuous presence of large COTS populations whose density is no longer closely related to coral recovery (e.g. in Japan) (Keesing 1993).

Three significant outbreaks have been recorded on the GBR in recent decades: in 1962 (first detected at Green Island), in 1979 (Green Island), and in 1993 (Lizard Island) (Moran 1986, Pratchett 2005) (see
Fig. 2). There are currently many COTS on reefs north of Cairns $\left(17^{\circ} \mathrm{S}\right)$, which may represent the start of a fourth wave of outbreaks (Brodie \& Waterhouse 2012). Genetic studies have established that outbreak cycles in the GBR have likely been due to a single 'source' outbreak which drifted southwards (Benzie 1992, Benzie \& Stoddart 1992).

Significant resources have been, are, and will be deployed towards controlling and eradicating COTS from the GBR, both in the short term (tactical measures) and in the long term (strategic management) Australia directs AUD \$3 million annually toward managing COTS outbreaks (Timmers et al. 2012). Emphasis has been placed on local-scale control, principally to protect high-value tourism sites, using various methods (cutting, manual removal, and poison injection), which have had limited success (Yamaguchi 1986, Johnson et al. 1990, Lassig et al. 1995, Fisk \& Power 1999, Bos et al. 2013). Ecological theory, such as Volterra's principle, would predict that removals may have the net result of encouraging the persistence of COTS populations, rather than controlling them, through release of the population from density-dependent effects (Weisberg \& Reisman 2008).

Modelling studies can contribute to understanding possible mechanisms leading to the development of primary outbreaks and can be used to evaluate the efficacy of alternative management strategies aimed at controlling outbreaks. Here, we develop a model of intermediate complexity for ecosystem assessments (MICE) (Plagányi et al. 2014) which serves to (1) describe the COTS-coral dynamics at one wellstudied location by fitting to data for that location and (2) evaluate the potential effects of short-term tactical strategies. In this respect, MICE are very useful tools, as they incorporate the best features of single-species models while taking into account broader ecosystem considerations, given a few well-defined objectives. Thus, our model includes several of the key functional groups of interest and, unlike more strategic ecosystem models, includes the ability to apply standard statistical methods for parameter estimation. Reduced complexity is further achieved because key predator-prey dependencies are modelled based on the effects of predator breeding success and survival factors on prey biomass rather than by explicitly describing all the consumption-related terms (Plagányi et al. 2014).

In this study, we review the literature on COTS outbreak hypotheses, describe a quantitative model of intermediate complexity (the 'base-case' model), and explore 3 control scenarios: (1) predation by large 
fish on adult COTS, (2) predation by benthic invertebrates on juvenile COTS, and (3) manual removal of adult COTS. In this way, through impartial comparison of alternative scenarios, we demonstrate the utility of a reduced-complexity MICE trophodynamic model in informing management decisions, and we establish a rigorous dynamic framework as a basis for future work.

\section{METHODS}

\section{Conceptual framework}

We reviewed alternative hypotheses put forward to explain COTS outbreaks to inform alternative conceptual models of the system, identify critical components that should be included in a quantitative model, and determine the model structure needed to explore alternative trophodynamic linkages and the efficacy of potential management solutions. Three main groups of hypotheses on the causes of COTS outbreaks have been put forward, but none has been fully supported or rejected by available data:

(1) Hypotheses related to natural causes are based on the observation that some traits of the biology of COTS (e.g. rapid growth, high fecundity, aggregative behaviour) cause this species to normally undergo wide fluctuations in population numbers in time and space without any anthropogenic input (Dana 1970, Moran 1986).

(2) Hypotheses related to enhanced larval survival incorporate both natural and anthropogenic components. These hypotheses are based on the notions that larval stages are food-limited under normal conditions (larval starvation hypothesis; Lucas 1982, Brodie 1992) and that larval survival is (i) enhanced by low salinities and high temperatures (Lucas 1973; larval recruitment hypothesis, Moran 1986), and (ii) intensified by phytoplankton production (and altered species composition) as a consequence of increased nutrients (natural and anthropogenic) derived from heavy rainfall and increased river inputs/terrestrial run-off (terrestrial run-off hypothesis; Birkeland 1982, Brodie 1992, Brodie et al. 2005, Fabricius et al. 2010). These hypotheses, and the proliferation in anthropogenic nutrient inputs (e.g. fertilizers and sewage) in the past century, may account for the hypothesised increased incidence of COTS outbreaks in recent decades and would provide strong grounds for a long-term, catchment-based management strategy (Brodie 1992).
(3) Predator-related hypotheses are based on the predator-removal hypothesis, which advances the idea that the removal of predators by human intervention releases predation pressure on the COTS, enhancing (juvenile and/or adult) survival (see McCallum 1987). Theoretical studies have found that the likelihood of any one predator being able to control COTS numbers depends on factors such as the type of predator-prey functional response (e.g. Type II vs. Type III), the type of predator (generalist vs. specialist), the density of COTS, and the type of outbreak (primary vs. secondary) (McCallum 1987, 1989, Ormond et al. 1990, Lassig et al. 1995). Densitydependent effects on predators and predation rate may thus be important in modulating outbreaking or non-outbreaking populations (Ormond et al. 1990). The predator-removal hypothesis essentially implies that COTS numbers will fluctuate with predator density and be indirectly correlated with fishing intensity or the presence (or not) of marine protected areas (MPAs), but COTS abundance is more likely to be linked to indirect trophic effects (trophic cascades) rather than direct effects (Dulvy et al. 2004, Sweatman 2008). The importance of post-settlement mortality in the dynamics of COTS primary outbreaks is a consistent thread in the literature; the phase most vulnerable to predation (possibly by benthic invertebrates) probably being the one between settlement and the switch to coral feeding (Zann et al. 1987, McCallum 1989, Keesing \& Halford 1992a,b, Sweatman 1995, 2008).

In reality, there is most likely a combination of some or all of these hypothetical mechanisms (Moran 1986, Birkeland \& Lucas 1990) that determines whether an outbreak will occur or not (Keesing \& Halford 1992a, Dulvy et al. 2004). Based on these hypotheses, we developed a conceptual model that dynamically represents a COTS population, its key prey and predators, as well as external (anthropogenic) impacting agents and drivers (e.g. MPAs, nutrients, manual removals). The quantitative model described in this study (the 'base-case' model) is contained within the more general conceptual model showing how the work presented here fits into the bigger picture (Fig. 1).

\section{Model structure}

Consistent with the MICE philosophy, we start simply and develop a quantitative model, the 'base-case' model, that describes trophic interactions between COTS and 2 groups of corals (fast- and slow-growing) 
given the available data (Fig. 1). The model time period runs from 1970 to 2011, and the model is fitted to data from Lizard Island (Fig. 2) available for COTS and corals from 1994 to 2011. Key features of the model include consumption of corals by COTS, which are in turn negatively affected by coral decrease. The equations driving these dynamics are summarised in Table 1, whilst Tables 2 \& 3 respectively list all the variables and parameters of the model and the rationale for their values. The model focuses on trophic interactions in COTS control and is used to evaluate the effectiveness of various control scenarios including predation by benthic invertebrates on juvenile COTS, predation by fish on adult COTS, and manual removal/poison injection of adult COTS. Although the model is not fitted to predator data, equations describing the dynamics of large fish and benthic invertebrates and terms for their consumption are used in the scenario projections and are thus also shown in Table 1.

An age-structured population model (e.g. Plagányi $\&$ Butterworth 2010) was used to represent COTS in 3 age classes: 0,1 , and $2+$ (Eq. $1 \mathrm{a}-\mathrm{C}_{;}$Table 1$)$. The representation of inter-specific interactions is based on the approach of Plagányi \& Butterworth (2012) and involves a multiplier for predator survival or breeding success (e.g. $f\left(C_{y}^{f}\right)$, Eq. 9; Table 1) to represent the impact of relative prey depletion. Hence, instead of a detailed mechanistic description of how the growth of COTS is affected by the consumption of their coral prey at each time step, the model focuses on the likely outcome of the interaction; in other words, the survival or breeding success of the COTS is modified based on the relative depletion of the prey, and the nature and extent of this relationship is estimated by fitting to data describing observed changes in population size following an interaction.

The number of age-0 COTS (or 'recruits' — animals in their first year of life) can be modelled as selfrecruitment $(R$, the number of settling larvae from the local spawning, as determined from the stockrecruitment relationship) and/or immigration ( $I$, the number of settling larvae transported to the region from elsewhere) (Eq. 1a; Table 1). This formulation assumes spawning occurs as a pulse at the start of the year (and similarly for an immigration pulse); these

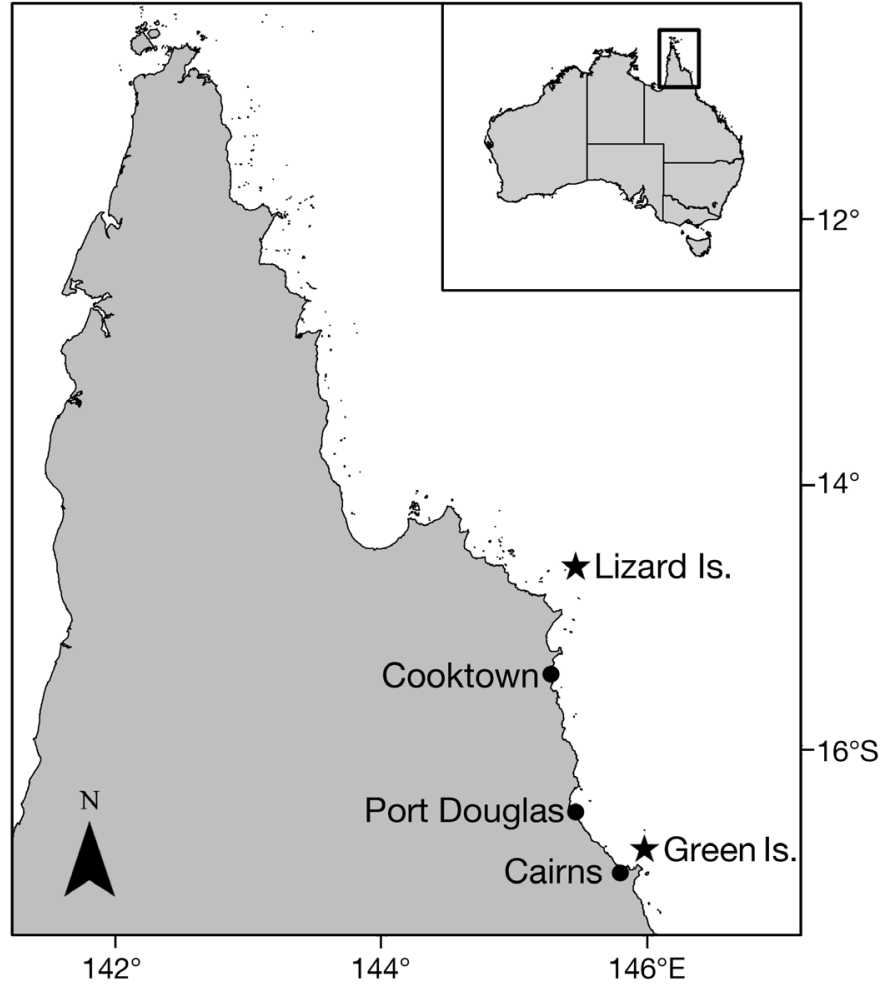

Fig. 2. Northern Queensland (Australia), showing the locations of Lizard Island and Green Island 
Table 1. Model equations for key groups (definitions of variables and parameters are shown in Tables $2 \& 3$ ) and the loglikelihood function. COTS: crown-of-thorns starfish

\begin{tabular}{|c|c|c|}
\hline Functional group & Equation & No. \\
\hline \multicolumn{3}{|l|}{ Basic population dynamics } \\
\hline $\begin{array}{l}\text { COTS } \\
\text { Age-0 }\end{array}$ & $N_{y+1,0}=R_{y+1}+I \mathrm{e}^{\eta_{y+1}} ; \quad R_{y}=\frac{4 h R_{0} N_{y, 2+} / K^{\operatorname{Cots}}}{(1-h)+(5 h-1) N_{y, 2+} / K^{\operatorname{Cots}}} \mathrm{e}^{\varepsilon_{y}}$ & $1 \mathrm{a}$ \\
\hline Age-1 & $N_{y+1,1}=N_{y, 0} \mathrm{e}^{-f\left(C_{Y}^{\mathrm{f}}\right) M^{\text {Cots }}}-Q_{Y, 0}^{\operatorname{Cots}}$ & $1 b^{\underline{a}}$ \\
\hline Age-2+ & $N_{Y+1,2+}=\left(N_{y, 1}+N_{y, 2+}\right) \mathrm{e}^{-f\left(C_{y}^{\mathrm{f}}\right) M^{\operatorname{Cots}}}-Q_{Y, 2+}^{\text {Cots }}-H_{Y}^{\text {Cots }}\left(\Phi_{1}^{\text {Cots }} N_{y, 1}+N_{y, 2+}\right)$ & $1 \mathrm{c}^{\mathrm{a}}$ \\
\hline Fast-growing coral & $C_{y+1}^{\mathrm{f}}=C_{y}^{\mathrm{f}}+r^{\mathrm{f}} C_{y}^{\mathrm{f}}\left(1-C_{y}^{\mathrm{f}} / K^{\mathrm{f}}\right)-Q_{y}^{\mathrm{f}}$ & 2 \\
\hline Slow-growing coral & $C_{y+1}^{\mathrm{m}}=C_{y}^{\mathrm{m}}+r^{\mathrm{m}} C_{y}^{\mathrm{m}}\left(1-C_{y}^{\mathrm{m}} / K^{\mathrm{m}}\right)-Q_{y}^{\mathrm{m}}$ & 3 \\
\hline Benthic invertebrates & $\bar{B}_{y+1}^{\mathrm{I}}=\bar{B}_{y}^{\mathrm{I}}+r^{\mathrm{I}} \bar{B}_{y}^{\mathrm{I}}\left(1-\bar{B}_{y}^{\mathrm{I}} / K^{\mathrm{I}}\right)-Q^{\mathrm{I}}$ & 4 \\
\hline Large fish predators & $P_{y+1}=P_{y} g\left(C_{y}^{\mathrm{f}}\right) S^{\mathrm{P}}\left(1-F^{\mathrm{P}}\right)+P_{y-T_{+1}^{\mathrm{P}}} R^{\mathrm{P}} g\left(C_{y-T_{+1}^{\mathrm{P}}}^{\mathrm{f}}\right)\left(S^{\mathrm{P}}\right)^{T^{\mathrm{P}}}$ & $5^{\underline{\mathbf{b}}}$ \\
\hline \multicolumn{3}{|c|}{ Trophodynamic interaction terms } \\
\hline \multicolumn{3}{|l|}{ Predation on COTS } \\
\hline Age-0 & $Q_{y, 0}^{\text {Cots }}=F^{\mathrm{I}} N_{y, 0} \bar{B}$ & $6 a$ \\
\hline $\begin{array}{l}\text { Age- } 2+ \\
\text { COTS predation on coral }\end{array}$ & $Q_{y, 2+}^{\text {Cots }}=\frac{p_{1}^{\text {Cots }} N_{y, 2+} P_{y}}{1+\mathrm{e}^{-N_{y, 2+} / p_{2}^{\text {Cots }}}}$ & $6 b$ \\
\hline Fast-growing & $Q_{y}^{\mathrm{f}}=\left(1-\rho_{y}\right) \frac{p_{1}^{\mathrm{f}}\left(N_{y, 1}+N_{y, 2+}\right) C_{Y}^{\mathrm{f}}}{1+\mathrm{e}^{-\left(N_{y, 1}+N_{y, 2}+\right) / p_{2}^{\mathrm{f}}}}$ & $7 a$ \\
\hline Slow-growing & $Q_{y}^{\mathrm{m}}=\rho_{y} \frac{p_{1}^{\mathrm{m}}\left(N_{y, 1}+N_{y, 2+}\right) C_{y}^{\mathrm{m}}}{1+\mathrm{e}^{-\left(N_{Y, 1}+N_{Y, 2+}\right) / p_{2}^{\mathrm{m}}}}$ & $7 b$ \\
\hline Switch function & $\rho_{y}=1+\mathrm{e}^{-5 C_{Y}^{\mathrm{f}} / K^{\mathrm{f}}}$ & 8 \\
\hline $\begin{array}{l}\text { Coral abundance } \\
\text { on COTS mortality }\end{array}$ & $f\left(C_{y}^{\mathrm{f}}\right)=1-\tilde{p} \frac{C_{y}^{\mathrm{f}}}{1+C_{Y}^{\mathrm{f}}}$ & 9 \\
\hline $\begin{array}{l}\text { Coral abundance } \\
\text { on predator survival }\end{array}$ & $g\left(C_{y}^{\mathrm{f}}\right)=1-\tilde{\tilde{p}} \frac{C_{y}^{\mathrm{f}}}{1+C_{y}^{\mathrm{f}}}$ & 10 \\
\hline $\begin{array}{l}\text { Sensitivity analyses } \\
\text { COTS mortality at age }\end{array}$ & $M_{a}=\omega+\frac{\lambda}{a+1}$ & 11 \\
\hline $\begin{array}{l}\text { The likelihood function } \\
\text { Negative log-likelihood } \\
\text { function }\end{array}$ & $-\ln L=\sum_{j}\left[\sum_{y} \ln \sigma_{y}^{j}+\left(\ln \left(I_{y}^{j}\right)-\ln \left(\hat{I}_{y}^{j}\right)\right)^{2} / 2\left(\sigma_{y}^{j}\right)^{2}\right]$ & 12 \\
\hline $\begin{array}{l}\text { Standard deviation of } \\
\text { the residuals for } \\
\text { functional group } j\end{array}$ & $\hat{\sigma}^{j}=\sqrt{\frac{1}{n_{j}} \sum_{y}\left(\ln I_{y}^{j}-\ln \hat{I}_{y}^{j}\right)^{2}}$ & 13 \\
\hline$I_{y}^{j}$ & The observed abundance or biomass of functional group $j$ in year $y$ & \\
\hline$\hat{I}_{y}^{j}$ & $\begin{array}{l}\hat{I}_{y}^{j}=q^{j} B_{y}^{\text {pred }, j} \text {, where } B_{y}^{\text {pred } j}, \text { is the predicted abundance or biomass } \\
\text { of functional group } j \text { in year } y \text {, and } q^{j} \text { is the constant of proportionality } \\
\text { for abundance/biomass series corresponding to each functional group } j\end{array}$ & \\
\hline $\begin{array}{l}\text { Constant of proportionality } \\
\text { for functional group } j \text { : }\end{array}$ & $\ln \hat{q}^{j}=\frac{1}{n_{j}} \sum_{y}\left(\ln I_{y}^{j}-\ln \hat{B}_{y}^{\mathrm{pred}_{, j}}\right)$ & 14 \\
\hline a $T h e$ terms $Q_{y, a}^{\text {Cots }}, H_{y}^{\text {Cots }}$, ar & $\Phi_{1}^{\text {Cots }}$ are set to 0 when fitting the base-case model & \\
\hline
\end{tabular}


Table 2. Description of the variables of the model. COTS: crown-of-thorn starfish

\begin{tabular}{|c|c|}
\hline $\begin{array}{l}\text { Functional } \\
\text { group }\end{array}$ & Description \\
\hline \multicolumn{2}{|l|}{ COTS } \\
\hline$N_{y, a}$ & $\begin{array}{l}\text { Number of COTS of age } a \text { at the start } \\
\text { of (calendar) year } y\end{array}$ \\
\hline$R_{y}$ & Self recruitment during year $y$ \\
\hline$Q_{Y, a}^{\operatorname{Cots}}$ & $\begin{array}{l}\text { Number of COTS of age a consumed } \\
\text { by predators during year } y \text { (age-0 COTS } \\
\text { by benthic invertebrates; age-2+ COTS } \\
\text { by large fish predators) }\end{array}$ \\
\hline$M_{a}$ & Natural mortality at age $a$ \\
\hline \multicolumn{2}{|c|}{ Fast-growing coral } \\
\hline$C_{y}^{\mathrm{f}}$ & $\begin{array}{l}\text { Biomass of fast-growing coral } \\
\text { at the start of year } y^{\underline{a}}\end{array}$ \\
\hline$Q_{Y}^{\mathrm{f}}$ & $\begin{array}{l}\text { Biomass of fast-growth coral consumed } \\
\text { by COTS during year } y\end{array}$ \\
\hline \multicolumn{2}{|c|}{ Slow-growing coral } \\
\hline & $\begin{array}{l}\text { Biomass of slow-growing coral } \\
\text { at the start of year } y^{\underline{a}}\end{array}$ \\
\hline$Q_{y}^{\mathrm{m}}$ & $\begin{array}{l}\text { Biomass of slow-growth coral consumed } \\
\text { by COTS during year } y\end{array}$ \\
\hline \multicolumn{2}{|c|}{ Benthic invertebrates } \\
\hline $\bar{B}_{Y}^{I}$ & $\begin{array}{l}\text { Mean biomass of benthic invertebrates } \\
\text { (assumed constant) }\end{array}$ \\
\hline \multicolumn{2}{|c|}{ Large fish predators } \\
\hline $\begin{array}{l}P_{Y} \\
\text { aAs percent } \\
\text { are 3D cons } \\
\text { biomass as }\end{array}$ & $\begin{array}{l}\text { Number of large fish predators } \\
\text { at the start of year } y \\
\text { ge cover is a } 2 \mathrm{D} \text { measure and corals } \\
\text { ructs, the } 2 \mathrm{D} \text { estimate is converted to } 3 \mathrm{D} \\
\text { ollows: Coral biomass = Coral cover }\end{array}$ \\
\hline
\end{tabular}

new recruits are then subject to natural mortality throughout the first year of their life, with those surviving then moving into age class 1 (Eq. 1a; Table 1). In terms of recruitment, this study considers one (of many possible) scenarios that may have occurred at Lizard Island: in most years, the bulk of age-0 COTS originates from the sum of low-level local selfrecruitment (the steepness parameter of the stockrecruitment relationship, $h$, is assumed to be 1 ) and low background immigration. In 1994, there is a large pulse of immigration and in 1996 a pulse of local self-recruitment. The model structure allows self-recruitment to be modelled deterministically, stochastically, or as a pulse, with the recruitment parameters estimated by fitting to available data. The natural mortality rate is applied to age-0 COTS to determine the number of newly settled recruits. Natural mortality for age-1+ COTS is assumed to depend on the abundance of fast-growing corals, where $f\left(C_{y}^{\mathrm{f}}\right)$ is a multiplier that accounts for this dependence (Eqs. 1b,c \& 9; Table 1). Conceptually, consumption of age-0 COTS is modelled as a function of the numbers of benthic invertebrates, whilst consumption of age-2+ COTS depends upon numbers of large fish predators (Table 1; Eq. 6a,b) which are assumed to switch to preying on COTS when COTS abundance increases beyond a threshold level. The term $H^{\text {Cots }}$ accounts for manual removals and/or poison injection of age-2+ COTS (Eq. 1c; Table 1). The base-case model does not include predation explicitly as there were no predator data to fit to; thus, the terms accounting for consumption and manual removal are all set to 0 (Table 1 ).

Two groups of corals are modelled: fast-growing coral (Acropora spp.) and massive slow-growing coral (e.g. Faviidae and Porites spp.) (Eqs. $2 \& 3$; Table 1). Massive corals are not the favourite prey of COTS, which switch to consuming them only at high densities or when fast-growing corals have dwindled (Birkeland \& Lucas 1990). Thus, COTS start consuming fast-growing coral and switch to slow-growing coral only when the density of fast-growing coral declines substantially (Eqs. 7a,b \& 8; Table 1).

Fish predation is assumed to be a constant component of the mortality term in the base-case model, but variable and higher predation rates are modelled explicitly in the projections. Thus, the numbers of large predatory fish are modelled using a delay-difference equation that includes a fishing mortality term, $F^{\mathrm{P}}$, and the model assumes that these fish consume predominantly age-2+ COTS (Eq. 5; Table 1). Eq. (5) includes a term, $g\left(C_{y}^{\mathrm{f}}\right)$, to modify adult fish survival as well as the product of juvenile survival and reproduction, as a function of the biomass of fast-growing coral (Eq. 10; Table 1). The number of COTS does not directly influence the number of large predators because no large fish are COTS-specialists, although the number of large predators is influenced indirectly by COTS through the relationship between fish survival and coral habitat. In the projections, the biomass of benthic invertebrates is assumed to be constant for the analyses of this paper (which focuses on presence versus absence of this group).

\section{Fitting the model to data}

The model was fitted to historical data for COTS and for fast-growing and slow-growing corals to estimate the parameters related to trophic interactions between these main groups. The data used were collected by the Australian Institute of Marine Science Long Term Monitoring Program at Lizard Island (Queensland, Australia) from 1994 to 2011 (with 
Table 3. Specification of the parameters of the model for the purposes of model fitting. N/A: not applicable, COTS: crown-of-thorn starfish

\begin{tabular}{|c|c|c|c|}
\hline \multicolumn{2}{|r|}{ Description } & Value & Rationale/Notes \\
\hline \multicolumn{4}{|l|}{ COTS } \\
\hline \multicolumn{2}{|c|}{$\operatorname{COTS}_{\text {init }}$ Initial number of age-2+ COTS } & Estimated & 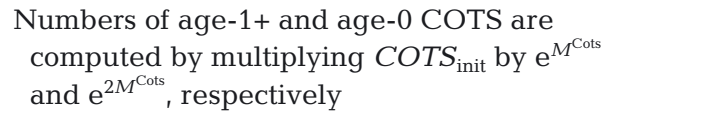 \\
\hline$\varepsilon_{y}$ & Stock-recruitment residual for year $y$ & 0 for all years except 1996 & Value for 1996 is estimated \\
\hline$I$ & Median background immigration & 1 & \\
\hline$\eta_{y}$ & Immigration residual for year $y$ & 0 for all years except 1994 & Value for 1994 is estimated \\
\hline$h$ & Stock-recruitment steepness & 1 & $\begin{array}{l}\text { Implies that self-recruitment is constant } \\
\text { in expectation }\end{array}$ \\
\hline$\Phi_{1}^{\text {Cots }}$ & $\begin{array}{l}\text { Selectivity of age } 1 \text { COTS applied } \\
\text { to manual removal }\end{array}$ & 0 & Non-zero values are considered in the projections \\
\hline$H_{y}^{\text {Cots }}$ & Annual proportion of age $2+$ COTS removed & 0 & Non-zero values are considered in the projections \\
\hline$R_{0}$ & Unfished recruitment & 1 & \\
\hline$K^{\text {Cots }}$ & Carrying capacity & N/A & $\begin{array}{l}\text { Does not impact the dynamics given } \\
\text { the assumed value for } h\end{array}$ \\
\hline$M^{\text {Cots }}$ & Natural mortality & Estimated & \\
\hline$p_{1}^{\text {Cots }}$ & Predation effect of large fish on COTS & 0 & Non-zero values are considered in the projections \\
\hline$p_{2}^{\text {Cots }}$ & Predation effect of large fish on COTS & 50 & Pre-specified as it is correlated with $p_{1}^{\text {Cots }}$ \\
\hline$\tilde{p}$ & Effect of fast-growing coral on COTS mortality & Estimated & \\
\hline$\omega$ & Mortality estimated by fitting the model & $2.560 \mathrm{yr}^{-1}$ & Natural mortality estimated by the base-case model \\
\hline$\lambda$ & $\begin{array}{l}\text { Parameter controlling the difference } \\
\text { between mortality rates of younger } \\
\text { and older animals }\end{array}$ & $0.1,0.2,0.3$, estimated & $\begin{array}{l}\text { Parameter } \lambda \text { can be either estimated or fixed } \\
\text { to a constant }\end{array}$ \\
\hline \multicolumn{4}{|c|}{ Fast-growing coral } \\
\hline$C_{\text {init }}^{\mathrm{f}}$ & Initial biomass & Set to $K^{\mathrm{f}}$ & \\
\hline$r^{\mathrm{f}}$ & Intrinsic rate of growth & $0.5 \mathrm{yr}^{-1}$ & Pre-specified after initial model tuning \\
\hline$K^{\mathrm{f}}$ & Carrying capacity & 2500 & Arbitrary $\underline{\mathbf{a}}$ \\
\hline$p_{1}^{\mathrm{f}}$ & Effect of COTS on fast-growing coral & Estimated & \\
\hline$p_{2}^{\mathrm{f}}$ & Effect of COTS on fast-growing coral & 10 & Pre-specified as it is correlated with $p_{1}^{\mathrm{f}}$ \\
\hline \multicolumn{4}{|c|}{ Slow-growing coral } \\
\hline$C_{\text {init }}^{\mathrm{m}}$ & Initial biomass & Set to $K^{\mathrm{m}}$ & \\
\hline$r^{\mathrm{m}}$ & Intrinsic rate of growth & $0.1 \mathrm{yr}^{-1}$ & 5 -fold lower than for fast-growing coral \\
\hline$K^{\mathrm{m}}$ & Carrying capacity & 500 & Arbitrary $\underline{\underline{a}}$ \\
\hline$p_{1}^{\mathrm{m}}$ & Effect of COTS on slow-growing coral & Estimated & \\
\hline$p_{2}^{\mathrm{m}}$ & Effect of COTS on slow-growing coral & 8 & Pre-specified as it is correlated with $p_{1}^{\mathrm{m}}$ \\
\hline \multicolumn{4}{|c|}{ Benthic invertebrates } \\
\hline$F^{\mathrm{I}}$ & Mortality rate on age- 0 COTS & 0 & Non-zero values are considered in the projections \\
\hline $\bar{B}^{\mathrm{I}}$ & $\begin{array}{l}\text { Mean biomass of benthic invertebrates } \\
\text { in year y }\end{array}$ & 0 & Absent in the historical analysis \\
\hline$r^{\mathrm{I}}$ & Intrinsic rate of growth & $1.5 \mathrm{yr}^{-1}$ & Arbitrary \\
\hline$K^{\mathrm{I}}$ & Carrying capacity & 1 & \\
\hline$Q^{\mathrm{I}}$ & Consumption of benthic invertebrates & 0 & Absent in the historical analysis \\
\hline \multicolumn{4}{|c|}{ Large fish predators } \\
\hline$P_{\text {init }}$ & Initial numbers & 10 & Arbitrary $\underline{\mathbf{a}}$ \\
\hline$S^{\mathrm{P}}$ & Survival rate & $0.8 \mathrm{yr}^{-1}$ & Average value for large fish in the region \\
\hline$T^{\mathrm{P}}$ & Age-at-maturity & 4 & Average value for large fish in the region \\
\hline$R^{\mathrm{P}}$ & Recruitment & 0.3905 & $\begin{array}{l}\text { Selected so that the population is in equilibrium } \\
\text { in the absence of fishing }\end{array}$ \\
\hline$\widetilde{\widetilde{p}}$ & Effect of fast coral on predator survival & 0 & Non-zero values are considered in the projections \\
\hline$F^{\mathrm{P}}$ & Fishery mortality on predators & 0 & $\begin{array}{l}\text { Ignored for the purposes of the simulations } \\
\text { of this study }\end{array}$ \\
\hline
\end{tabular}


some years missing; Sweatman et al. 2008). Lizard Island was selected as the case study site for this study because (1) it is thought to have been the source reef for the 1993 COTS outbreak (Pratchett 2005), (2) there have been a number of detailed studies of this outbreak and its impacts on coral (Pratchett $2005,2010)$ as well as on the monitoring of manual removals and poison injections (Fisk \& Power 1999), (3) the 2013 Long Term Monitoring Program surveys classified it as currently having an incipient COTS outbreak (density $>0.22$ COTS manta tow ${ }^{-1}$; Miller et al. 2009), and (4) throughout the years, parts of Lizard Island have been progressively protected, resulting in one-third of the island being open to fishing since 2004, and this will prove useful when modelling the effects of fishing effort and MPAs on COTS outbreaks in future work.

The data were COTS counts manta tow ${ }^{-1}$, percentage cover of Acropora spp., and percentage cover of massive slow-growing coral forms (based on visual census; Sweatman et al. 2008). As percentage cover (of both coral functional groups) is a 2-dimensional (2D) measure, we assumed that coral biomass would be better represented by a 3D estimate of coral volume (Table 2).

The fitting was done by minimizing the negative of a log-likelihood function in which the observed data were assumed to be log-normally distributed about the model predictions (Eqs. $12 \& 13$; Table 1). The extent of variation about each of the 3 data series (time-series of estimates of density for COTS, fastgrowth corals, and slow-growing corals) was also estimated $(\sigma)$ during the model-fitting process (Eq. 13; Table 1). A common averaged $\sigma$ value was estimated for the 2 coral groups because the data are from the same survey. The model was implemented using AD Model Builder, which uses quasi-Newton automatic differentiation for statistical inference (Fournier et al. 2012). For converged model solutions,
Hessian-based standard error estimates were computed to assess the precision with which the various parameters could be estimated. We considered a parameter to be reliably estimated if the coefficient of variation $(\mathrm{CV})$ was $<0.5$ and classified parameters as poorly-estimable if the $\mathrm{CV}$ exceeded 1. Akaike's information criterion (AIC) was used as the model selection criterion and to assess how many parameters could be estimated.

Sensitivity analyses were carried out to (1) test the robustness of model results to alternative model configurations and (2) investigate the impact of using different values of COTS natural mortality $(M)$ and different approaches to its estimation. Thus, the model was run under the following conditions:

(1) The base-case, estimating 7 parameters, including COTS natural mortality, $M^{\text {COTS }}$;

(2) Including the estimation of extra parameters. The difficulties of estimating interaction parameters have been recognised (e.g. Blamey et al. 2013). Sensitivity analyses illustrate this by estimating the effect of fast-growing coral on COTS parameter $2\left(p_{2}^{\mathrm{f}}\right.$, Eq. 7a; Table 1) and separately estimating the effect of slow-growing coral on COTS parameter $2\left(p_{2}^{\mathrm{m}}\right.$, Eq. 7b; Table 1);

(3) Testing the sensitivity of the model to different values for $M^{\text {COTS }}$ : we report the results of 2 model versions, one with a fixed value of $M^{\text {COTS }}=2.1 \mathrm{yr}^{-1}$, and one with a fixed value of $M^{\mathrm{COTS}}=1.1 \mathrm{yr}^{-1}$;

(4) Testing the effect of assuming mortality is agedependent, using a functional form where COTS natural mortality at age $a, M_{a}$, is calculated from the mortality estimated by fitting the model (parameter $\omega)$ and scaled by a parameter $(\lambda)$ that controls the difference between the mortality rates of younger and older animals (Eq. 11; Table 1). Parameter $\lambda$ can be either estimated or fixed to a constant. We report the results of model versions where parameter $\lambda$ was fixed to values of 0.2 and 0.3 , as well as estimated.

Table 4. Parameters defining the 3 projection scenarios. When multiple values were explored, these are specified separated by commas

\begin{tabular}{|c|c|c|c|}
\hline \multirow[t]{2}{*}{ Parameter, description } & \multicolumn{3}{|c|}{ - Scenario } \\
\hline & 1 & 2 & 3 \\
\hline$\tilde{\tilde{p}}_{\text {, effect of fast-growing coral on predator survival }}$ & $0.2,0.3$ & - & - \\
\hline$p_{1}^{\text {Cots }}$, predation effect of large fish on COTS & $0.01,0.03$ & - & - \\
\hline $\bar{B}_{y,}^{\mathrm{I}}$ benthic invertebrates (presence/absence) & 0 & 1 & - \\
\hline$F^{\mathrm{I}}$, mortality rate on age-0 COTS & 0 & $\begin{array}{c}0.000,0.025,0.050 \\
0.075,0.100,0.150\end{array}$ & - \\
\hline$\Phi_{1}^{\text {Cots }}$, selectivity of manual removal for age-1 COTS & - & - & $0.1,0.5$ \\
\hline$H_{y}^{\text {Cots }}$, annual proportion of age- $2+$ COTS removed annually & - & - & $0.0,0.1,0.9$ \\
\hline
\end{tabular}




\section{Projections}

Twenty-year deterministic projections were undertaken starting in 2011. The projections started under the assumption that there were negligible numbers of predatory fish, mimicking a situation in which a no-take zone had just been implemented (i.e. resources were depleted following fishing). Thus, with the establishment of a no-take zone, there would be an increasing number of large fish feeding on small fish, indirectly allowing benthic invertebrates to increase. An assumption in these projections was that a new immigration pulse (by seeding recruits into the model with the same magnitude as in 1994) of COTS larvae would invade in 2013, leading to an almost identical outbreak pattern. Three scenarios were considered (Table 4); each scenario involved the addition of 1 source of mortality on COTS:

Scenario 1 simulated predation of age-2+ COTS by large fish, in the absence of benthic invertebrates and manual removal and/or poisoning. Three combinations of 2 parameters were explored: (i) the interaction parameter $p_{1}^{\text {Cots }}$, which determines the rate of predation on COTS by large fish (Eq. 6b; Table 1), and (ii) the parameter $\widetilde{\tilde{p}}$, which determines the effect of the amount of fast-growing coral on survival and reproduction rate of large predatory fishes (Eq. 10; Table 1).

Scenario 2 simulated predation of age-0 COTS by benthic invertebrates, in the absence of fish predators and manual removal and/or poisoning; to do this, 6 different mortality rates were tested (Table 4).

Scenario 3 evaluated the effect of manual removals and/or poison injections of different proportions of age-1 and age-2+ COTS in the absence of large fish and benthic invertebrate predation. Given that suitable data on historical removals were not available, simulations were run across a broad range of hypothetical manual removal intensities (Eq. 1c, Table 1; Table 4).

\section{RESULTS}

\section{Fits to historical data}

The base-case MICE model successfully reproduces plausible trophic interactions between COTS and 2 groups of coral (fast- and slow-growing) at Lizard Island over the period 1970 to 2011. The best fit obtained using the AD Model Builder estimation routines is seen to reproduce the Lizard Island data adequately by estimating 7 parameters a) COTS

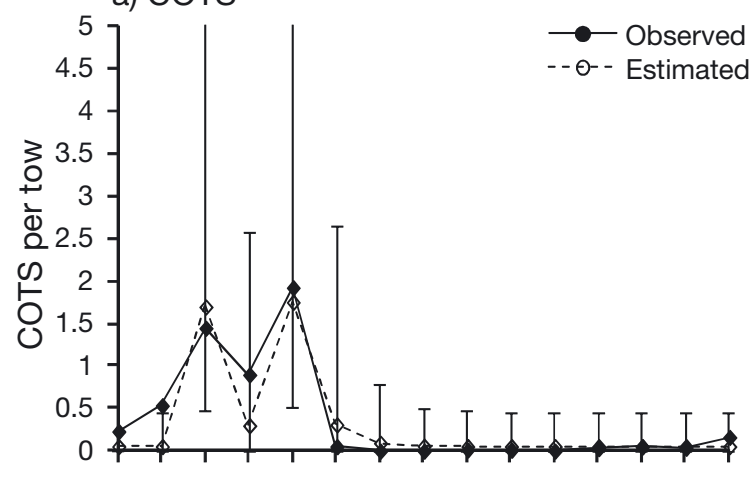

b) Fast-growing coral

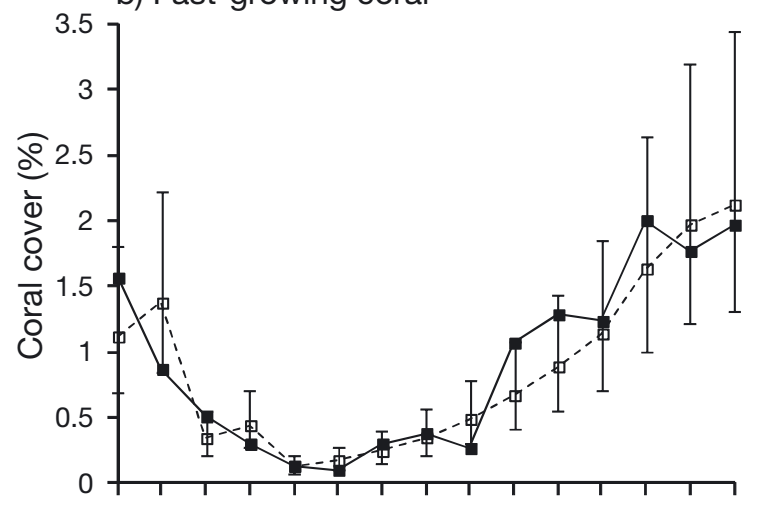

c) Slow-growing coral

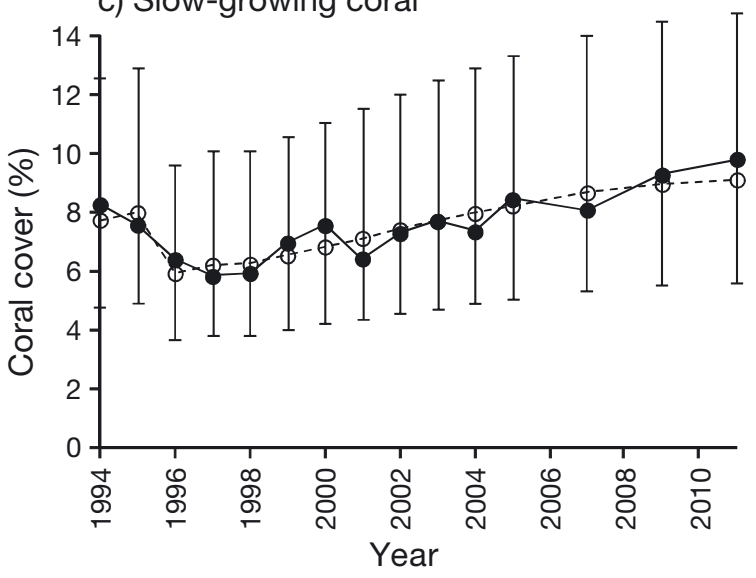

Fig. 3. Observed data from Lizard Island (black symbols and solid line) from 1994 to 2011 for (a) crown-of-thorns starfish (COTS), (b) fast-growing coral, and (c) slow-growing coral, and the respective values estimated by the model when fitted to these data (open symbols and dashed line). The vertical bars denote $95 \%$ confidence intervals for the observed data

(Fig. 3, Table 5). The Lizard Island data has 2 peaks in adult COTS: one in 1996 and another in 1998. The 1996 peak was explained as the result of an immigration $(I)$ pulse of age-0 COTS in 1994, and the 1998 peak is most likely the result of a local self-recruitment $(R)$ event in 1996. The extent 
Table 5. Results of the base-case model, including estimates, asymptotic standard errors (SD), and coefficients of variation (CV) of the estimable parameters, negative loglikelihoods ( $-\operatorname{lnL})$, associated calculated variances of the survey errors $(\sigma)$, and Akaike's information criterion (AIC)

\begin{tabular}{|c|c|c|c|c|c|}
\hline $\begin{array}{l}\text { Para- } \\
\text { meter }\end{array}$ & \multicolumn{2}{|l|}{ Description } & Value & $\mathrm{SD}$ & $\mathrm{CV}$ \\
\hline \multicolumn{6}{|l|}{ COTS } \\
\hline $\operatorname{COTS}_{\text {init }}$ & \multicolumn{2}{|c|}{ Initial number of $2+\mathrm{COTS}$} & 0.505 & 0.119 & 0.24 \\
\hline$\varepsilon_{y}$ & \multicolumn{2}{|c|}{ Stock-recruitment residual for year 1996} & 4.307 & 0.378 & 0.09 \\
\hline$\eta_{y}$ & \multicolumn{2}{|c|}{ Immigration for year 1994} & 4.292 & 0.352 & 0.08 \\
\hline$M^{\text {Cots }}$ & \multicolumn{2}{|c|}{ Natural mortality rate } & 2.560 & 0.146 & 0.06 \\
\hline \multicolumn{6}{|c|}{ Fast-growing coral } \\
\hline$p_{1}^{\mathrm{f}}$ & \multicolumn{2}{|c|}{ Effect of COTS on fast-growth coral } & 0.129 & 0.041 & 0.32 \\
\hline$\tilde{p}$ & \multicolumn{2}{|c|}{ Effect of fast-growing coral on COTS } & 0.258 & 0.167 & 0.65 \\
\hline \multicolumn{6}{|c|}{ Slow-growing coral } \\
\hline$p_{1}^{\mathrm{m}}$ & \multicolumn{2}{|c|}{ Effect of COTS on slow-growing coral } & 0.268 & 0.106 & 0.40 \\
\hline \multicolumn{2}{|c|}{ Likelihood } & \multicolumn{2}{|l|}{ Value } & \multicolumn{2}{|l|}{$\sigma$} \\
\hline \multicolumn{2}{|c|}{ No. parameters estimated } & 7 & & & \\
\hline \multicolumn{2}{|c|}{$-\operatorname{lnL}($ overall) } & -19.704 & & & \\
\hline \multicolumn{2}{|c|}{$-\operatorname{lnL}(\mathrm{COTS})$} & 8.374 & & 1.096 & \\
\hline \multirow{2}{*}{\multicolumn{2}{|c|}{-lnL(fast-growing coral) }} & -14.039 & & 0.246 & \\
\hline & & -14.039 & & 0.246 & \\
\hline \multicolumn{2}{|c|}{$\begin{array}{l}\text {-lnL(slow-growing coral) } \\
\text { AIC }\end{array}$} & -25.408 & & & \\
\hline
\end{tabular}

ferred one (Table S2), nor were the models with alternative fixed values of $\lambda(0.2$ and 0.3$)$ (Table S2). For example, when $\lambda=0.3$, the best estimate of $\omega$ was $2.276 \mathrm{yr}^{-1}(\mathrm{SD}=0.0001)$ with corresponding age-specific mortality estimates of $M_{0}=2.576 \mathrm{yr}^{-1}, M_{1}=$ $2.426 \mathrm{yr}^{-1}$, and $M_{2}=2.376 \mathrm{yr}^{-1}$, but this model was not preferred based on the AIC (Table S2).

\section{Projections}

Scenario 1 results suggested that large fish predators feeding on COTS may effectively reduce the amplitude of annual peaks of adult COTS numbers if consumption rates are modelled as sufficiently high (interaction parameter $p_{1}^{\text {Cots }}=0.03$ vs. 0.01 ; Fig. $4 \mathrm{a}$ vs. Fig. 4b). However, this change does not have a major impact on coral recovery given that coral recovery trajectories under the 3 different sce-

of self-recruitment was set at 0 for the remaining years. The values for the parameters estimated when fitting to the Lizard Island data and their asymptotic standard errors are listed in Table 5. The parameters are estimated with reasonable precision (CVs ranging from 0.10 to 0.65 ; Table 5), with those related to COTS immigration/self-recruitment estimated most precisely and those related to trophic interactions least precisely. The sensitivity analyses carried out to investigate the robustness of the base-case model showed that, based on the negative log-likelihood and AIC, this is the preferred model (see Table S1 in the Supplement at www.int-res.com/articles/suppl/m512p167_supp.pdf). The estimation of extra parameters (e.g. parameters $p_{2}^{\mathrm{f}}$ and $p_{2}^{\mathrm{m}}$, the effects of fast- and slow-growing coral on COTS, respectively) did not yield better model fits (similar negative log-likelihoods and reduced AICs).

The high value for COTS $M\left(2.56 \mathrm{yr}^{-1}\right)$ estimated by the base-case model is consistent with the rapid decline in COTS abundance (Fig. 3). Sensitivity analyses using alternative values for $M$ as well as an agedependent mortality factor $(\lambda)$ yielded models that were not preferred based on the AIC (see Table S2 in the Supplement). When testing the effect of assuming $M$ to be age-dependent, the model was able to reliably estimate $\lambda$, but this model was not the pre- narios are not distinguishable from one another (Fig. 4d). Furthermore, it is difficult to distinguish between COTS decline due to predation and decline due to reliance of large fish on fast-growing coral in terms of recruitment success (interaction parameter $p_{1}^{\text {Cots }}$ vs. interaction parameter $\widetilde{\tilde{p}}_{;}$Fig. $4 \mathrm{a}-\mathrm{c}$ ).

Predation of different proportions of age-0 COTS by benthic invertebrates (Scenario 2) is suggestive of strong impacts of these predators on both older COTS (Fig. 5a,b) and on coral decline and recovery (Fig. 5c). The annual removal of $15 \%$ of age-0 COTS appears to be sufficient to maintain the age-2+ population of COTS at levels that do not affect fastgrowing coral.

Once an outbreak is already occurring, manually removing and/or injecting age-1 and age-2+ COTS (Scenario 3) has minimal impact on overall population dynamics; even the removal of $50 \%$ of age-2+ COTS and $90 \%$ of age-1 COTS does not seem to help release fast-growing coral from the effects of COTS predation (Fig. 6).

Projections investigating the effects of combinations of the factors assessed in Scenarios 1, 2, and 3 led to results that were almost identical to the single factor projections, with only predation by benthic invertebrates able to control COTS abundance and hence impacts on fast-growing coral (results not shown). 

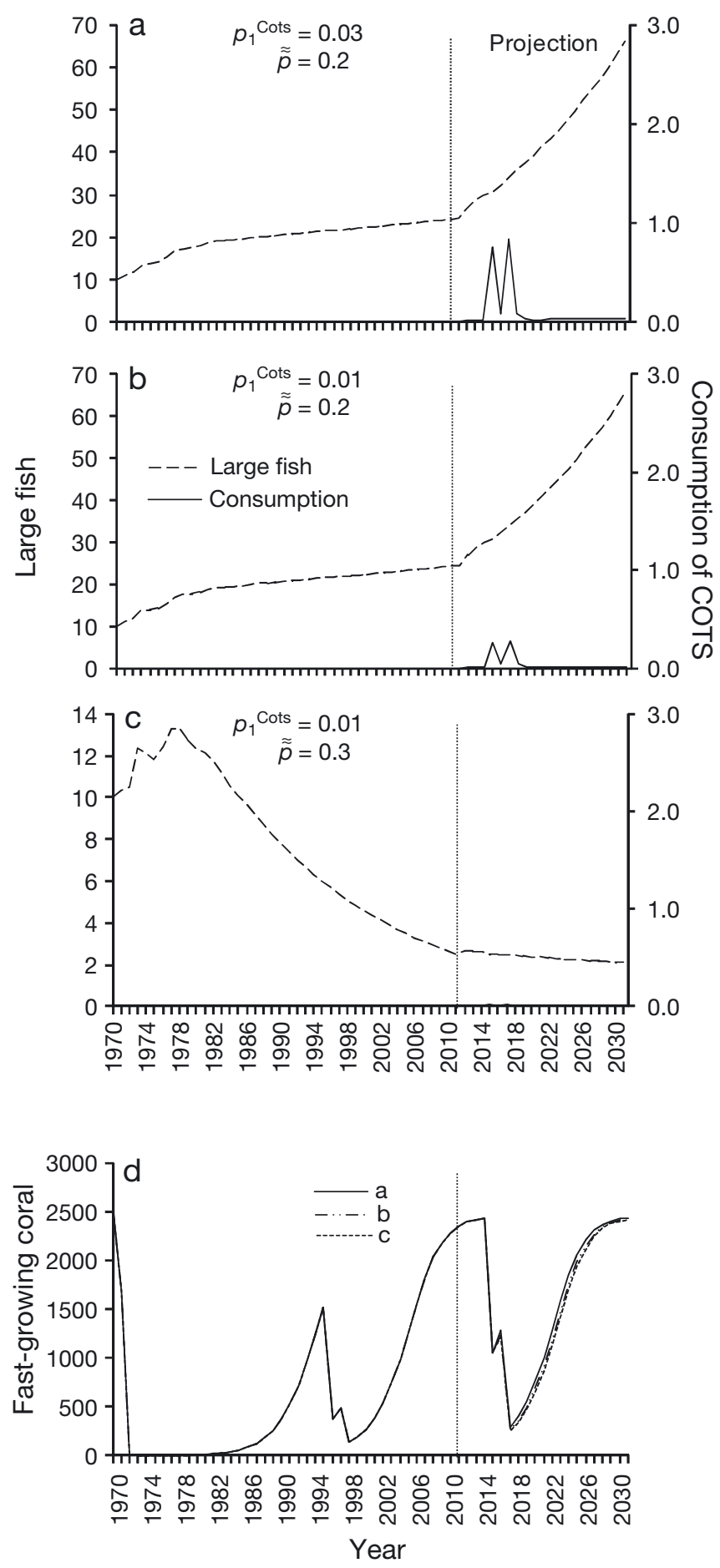

Fig. 4. Results for the historical period (1970-2010) and of the projections (2011-2031) carried out to evaluate Scenario 1 (see 'Methods: Projections'), showing $(\mathrm{a}-\mathrm{c})$ different combinations of the interaction parameters $p_{1}^{\text {Cots }}$ (predation by large fish on COTS) and $\widetilde{p}$ (effect of fast-growing coral on large predatory fish). Dashed lines represent large fish numbers, and solid lines represent COTS consumption. Also shown is (d) the overall effect of each combination of parameters on the dynamics of fast-growing coral. Scales are relative
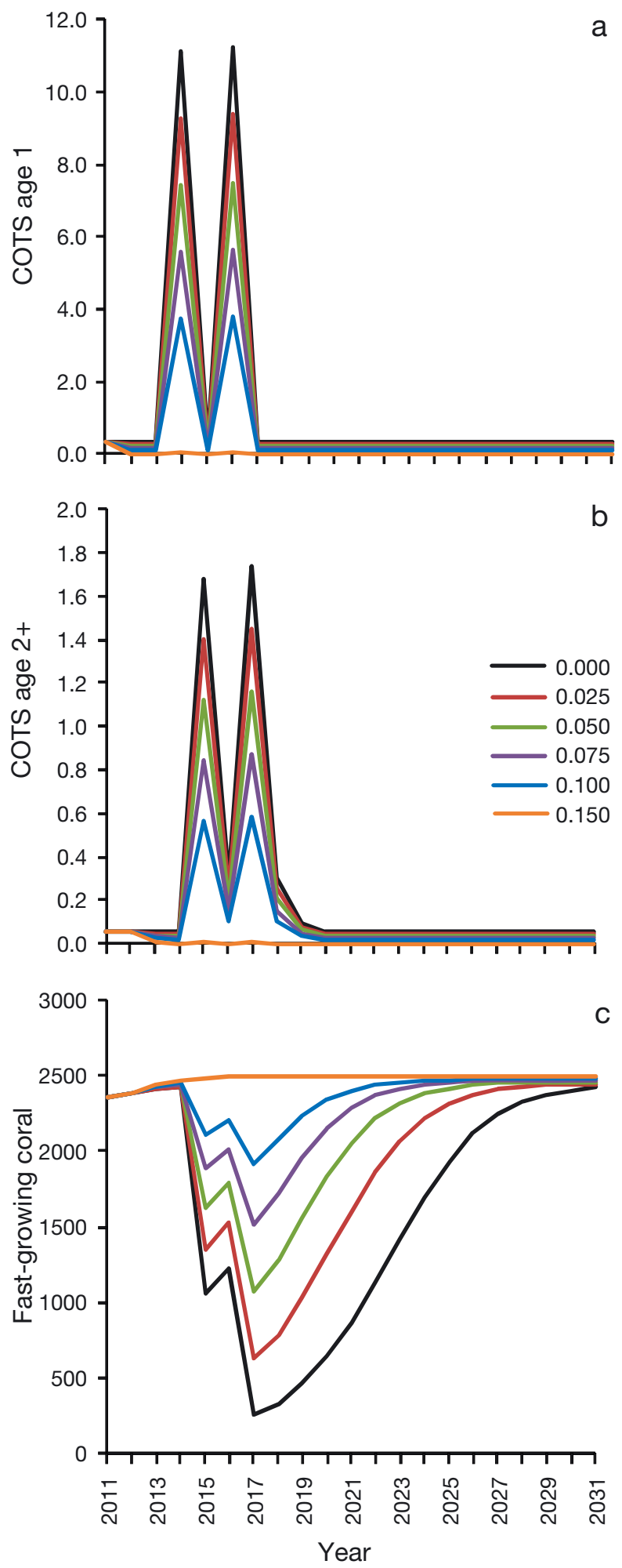

Fig. 5. Projections (2011-2031) for Scenario 2 (see 'Methods: Projections'), the effect of predation of different proportions $(0.00,0.025,0.050,0.075,0.100,0.150)$ of age-0 COTS by benthic invertebrates, showing the repercussions on (a) age1 and (b) age-2+ COTS and on (c) the abundance of fastgrowing coral. Scales are relative 

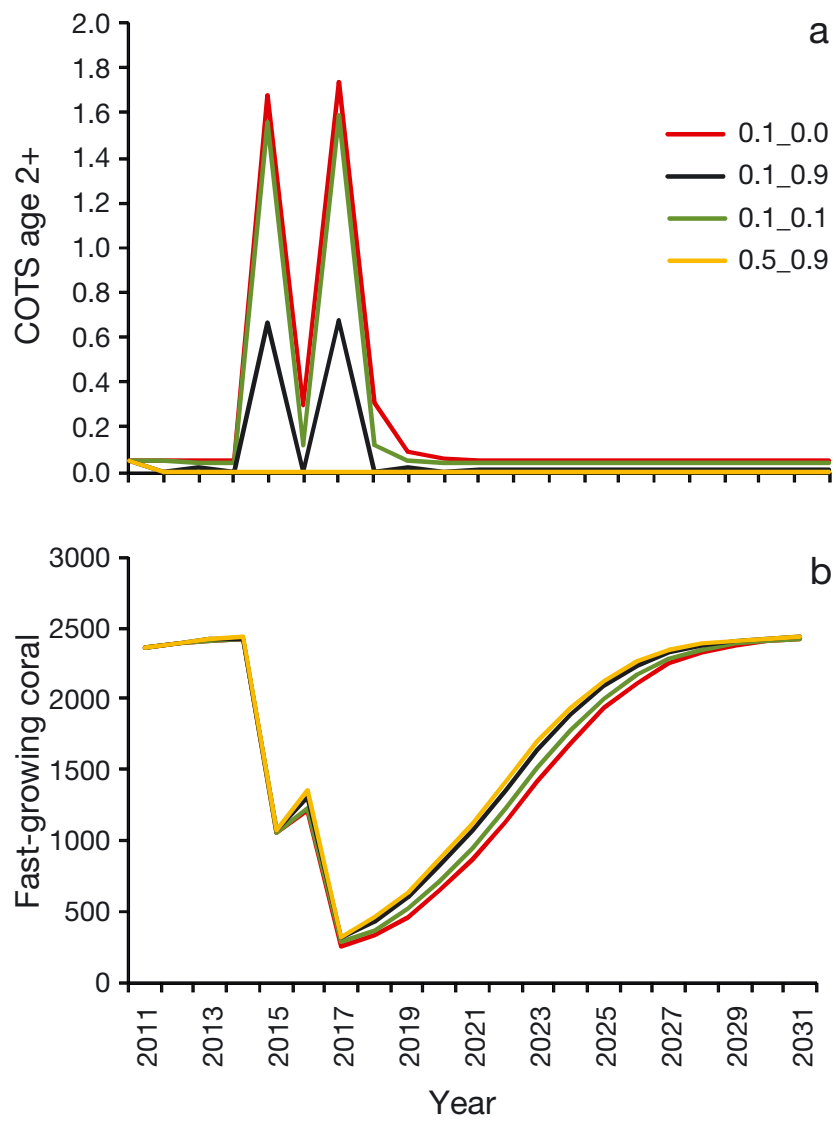

Fig. 6. Projections (2011-2031) for Scenario 3 (see 'Methods: Projections'), the effect of manual removal of different proportions of age-1 and age-2+ COTS (0.1_0.0, 0.1_0.1, $0.1 \_0.9,0.5 \_0.9$ ), showing the repercussions on (a) age-2+ COTS and (b) the impact on fast-growing coral. Scales are relative

\section{DISCUSSION}

The waves of outbreaks of COTS on the GBR and elsewhere have been a major management problem for decades, making them the focus of countless studies. Despite this, the cause(s) of the outbreaks in the GBR are yet to be fully understood, and effective control and/or mitigation strategies are still to be identified. The aim of our modelling study was to construct a model that is fitted to data, use it to describe the COTS-coral interaction, and simulate several removal scenarios on the basis of the reviewed outbreak hypotheses, providing a platform for the future evaluation of outbreak hypotheses and related management strategies. In particular, in this study, we assess the impacts and effectiveness of COTS removals, by natural (predation) or anthropogenic (poison injection) means.

To do this, we used a model of intermediate complexity for ecosystem assessments (MICE). One ad- vantage of using this approach is the relative simplicity with which complex trophodynamic interactions can be depicted. The formulation we used was flexible enough to model COTS switching prey from fastgrowing coral to slow-growing coral as the density of fast-growing coral declines. This same formulation could be applied in the future when, for example, describing the behaviour of fish predators switching to prey on COTS when COTS abundance increases beyond a threshold level. As with almost all ecosystem models, there were insufficient data to describe temporal changes in every component of the system, in this case the fish and invertebrate abundances. However, a long time-series of data on COTS and 2 groups of corals enabled estimation of parameters describing the population dynamics and inter-specific interactions between these 3 key groups. In the first instance, this enabled a dynamic representation of the COTS-coral system in a self-consistent manner, allowing us to understand which of the population dynamics hypotheses are consistent with the available data (for example: Can the second peak in COTS numbers be explained by self-recruitment? Can the declines in both coral cover types be explained by COTS predation?). This representation in turn served as a basis for investigating the impacts of different levels of fish, human, and/or invertebrate removals on different life stages of the COTS and hence the predicted impact on coral recovery trajectories. Although these projections are uncertain (as with any model or statistical prediction), they are a first step at quantifying the likely outcomes. Further, the model is helpful in identifying where additional data are required and how information on model structure needs to be improved to reduce uncertainty in predictions.

Thus, we fitted the model to data and reproduced both the historical coral decline observed in response to a COTS outbreak and the timing and magnitude of the subsequent recovery of 2 types of coral (fast- and slow-growing). Although the coral recovery rates depend largely on the growth rate parameters used, which vary among coral species and locations, 2 COTS-coral interaction parameters and 1 coralCOTS interaction parameter were well estimated by the model (see Table 5). The estimation of interaction parameters is difficult (Blamey et al. 2013) and cannot be achieved in many multispecies models, in part due to a lack of contrast in the data to fit the model. Our model not only yields fairly precise estimates of 3 interaction parameters but is also capable of describing a realistic 2 -way interaction between COTS and fast-growing coral. 
The base-case model provides an estimate of natural mortality of COTS. This is rather high $(M=$ $2.56 \mathrm{yr}^{-1}$ or $94 \%$ ) for an animal that can live for 7 to $8 \mathrm{yr}$, and if food (e.g. corals) is not limiting in an area, the natural mortality rate of a local COTS population could be expected to be lower. However, under outbreak conditions, populations characteristically decline rapidly, and most COTS do not live to maximum age (Moran 1986). Where there is a 2-way interaction between COTS and their prey (as seems very possible because of the linked declines in COTS following the decline in coral), the rapid decline in the COTS population model (and in the observed data) can only be explained by a high natural mortality rate. The COTS decline could be due to a number of mortality components, acting singly or in combination: starvation (possible because of the linked declines in coral prey), predation (difficult to distinguish from other mortality sources), senescence or disease (Pratchett $2005,2010)$. In the absence of sufficient data to make the distinction(s), the mortality estimated by the base-case model has to be assumed as being a combination of all possible sources of natural mortality. Because it provides the best fit to the data (based on the total likelihood and model selection criteria) and it is estimated fairly precisely (as evident from the Hessian-based standard errors), the high $M$ estimate can reliably be considered a suitable choice of parameter value to explain the dynamics observed at Lizard Island.

The role of self recruitment vs. immigration is central to resolving hypotheses related to COTS outbreaks. Here, we have examined one possible combination in order to explain the peaks in adult COTS observed at Lizard Island in 1996 and 1998. Although the model fit implies that the second peak in the COTS data is consistent with a hypothesis of selfrecruitment, it is not possible, without further investigations, to rule out the alternative possibility that this represented a second immigration event. The model was thus initialised with recruitment pulses of different origins in different years (immigration and self-recruitment), serving as examples of how the observed pulses could be modelled. Different combinations could have been used, highlighting a clear need to better understand factors that affect recruitment dynamics (closed vs. open populations) and their timing.

A number of projection scenarios were used to assess the effectiveness of natural versus anthropogenic control. For example, we were interested in assessing how effective fish predators might be in controlling COTS numbers if fish predators were abundant (e.g. if their numbers increased in a notake zone and they could switch to feeding on COTS when they become abundant). Hence, the simulations tested the effect of adding an additional source of mortality (in the form of predation by large fish), across a range of alternative interaction strengths, and whether predation could significantly impact COTS and coral populations. This could, in turn, reveal whether management measures could focus on increasing fish abundance as a COTS control measure.

Simulation of the effects of predation on different COTS life stages (post-settlement vs. adults) led to very different results, while simulating the removal and/or injection of adult COTS and the predation of adult COTS by large fish had similar effects on coral recovery. We found that high consumption rates by large fishes did dampen adult COTS numbers, but not enough to produce any tangible positive outcomes for coral. Similarly, removal or injection of various proportions of adult COTS in outbreaking populations did not appear to have any substantial effects on coral recovery. In contrast, we found predation by benthic invertebrates on juvenile COTS (age-1) might have a very strong impact on subsequent adult COTS populations, with positive effects on coral cover.

Our model has made a first attempt at describing the local dynamics in the effects of predation of 2 different groups of predators (fish vs. invertebrates) on 2 life stages of COTS (adult vs. juvenile). Our results appear to confirm the potential for fish to control the COTS adult population indirectly, though they did highlight the difficulties encountered when trying to model these dynamics. The decline in COTS numbers due to predation by large fishes was confounded with the decline in COTS numbers due to reliance on fast-growing coral for recruitment success, and these effects could not be distinguished with the available data. This points to the importance of data to resolve these issues and also to enable conversion of relative parameter estimates such as those related to carrying capacities into absolute numbers. Nevertheless, our modelling results suggest that predation alone cannot account for the rate and extent of the observed COTS decline. These results also suggest that if predation or the control of adults were to inhibit COTS outbreaks, this would likely be through reductions in self-seeding recruitment.

Most authors have ruled out predation of COTS adults as a control mechanism, in favour of that of predation of juveniles by fish such as lethrinids (Ormond et al. 1990, Sweatman 1995). Nevertheless, most information on predation of COTS by lethrinids 
is anecdotal; no field experiments carried out to date have unequivocally demonstrated predation of juvenile COTS by these fish, nor have COTS been systematically found in their gut contents (Sweatman 1995, 1997). Keesing \& Halford (1992a,b) and Sweatman (1995) suggested and investigated the role of benthic invertebrates in this predator-prey interaction, demonstrating it with varying levels of success and concluding that the juvenile algal feeding stage is likely to be a key life-history stage in this regard (Keesing et al. 1995). Given the apparent improbability that any form of control of adult COTS will directly prevent declines in coral cover, there is an urgent need to better identify the major predators of juvenile COTS.

The first theoretical work on the effects of predation on COTS outbreaks was by McCallum (1987, 1989), who investigated different functional responses (Type II vs. Type III sensu Holling 1959) and the effects of patchiness in the prey population, progressively introducing complexity (e.g. age-structure of the COTS population). McCallum (1987, 1989) established that there were generally multiple alternative stable states of COTS, where predators either managed to limit COTS numbers or were swamped by them. However, the extent of predator success depended on the interaction between the functional response assumed and the type of connectivity that existed among patches (symmetrical vs. asymmetrical systems; source vs. sink patches). The importance of predation on juvenile, post-settlement COTS by predators having a Type III functional response suggests that predator searching behaviour at low prey densities is a crucial factor in understanding the dynamics of COTS, as is the quantification of predator-induced mortality rates at low adult densities (McCallum 1987, 1989, Bradbury et al. 1990, Ormond et al. 1990, van der Laan \& Bradbury 1990). Ormond et al. (1990) went further and suggested the concept of 'recruitment initiated predation' whereby significant predation of COTS juveniles would only happen following heavy local recruitment. Reef connectivity may also be important in determining whether predator control could be effective at different recruitment densities. Under certain conditions (e.g. a nearby source reef and good larval mixing), even Type II predation may be able to maintain low COTS populations (McCallum 1990). Van der Laan \& Bradbury (1990) and Bradbury et al. (1990) found that varying levels of connectivity (and larval survival) induced distinct outbreak types and that different types of juvenile COTS predators ('neutral filter' vs. Type III) modulated the outcomes differently. In the absence of predators, their models predicted local/incidental outbreaks at low connectivity, (southward) travelling wave outbreaks (sensu Reichelt et al. 1990) at medium connectivity, and the new concept of global pulse outbreak (system-wide, simultaneous outbreak-recovery cycles) at high connectivity. This pattern was the same in the presence of 'neutral filter' predators (i.e. qualitatively present or absent), although the number of affected reefs decreased.

Considering the results we obtained when simulating the effects of adult COTS predation by large fish, the poor response of COTS and coral to the manual removal of adult COTS was not surprising. Management of COTS using the laborious and costly methods of manual removal or poisoning of adults has been fraught with small- and large-scale failures (Birkeland \& Lucas 1990). Large-scale control programs appear to have been especially unsuccessful (e.g. the Ryuku archipelago, Japan), whilst smallscale programs have yielded some partial (e.g. Honshu, Japan in 1987) and few complete (e.g. Guam in 1986) success stories (Birkeland \& Lucas 1990). Success depends on how early the outbreak is detected, how rapid the response is, how small and isolated the affected area is, how large and aggregated the COTS population is and whether control is carried out before the spawning period (Birkeland \& Lucas 1990, Bos et al. 2013). Our MICE model could be a useful tool in understanding the implications of these different management strategies giving managers an idea as to which measures are most worth investing in.

\section{COTS and MICE into the future}

The MICE model described here could be further developed to become a very useful tactical tool for understanding the implications of different management strategies in light of the alternative hypotheses that might explain COTS outbreaks.

Consistent with the MICE philosophy, we started relatively simply by building a platform that lends itself to expansion. Complexity can be added incrementally. The results of our projections of the impact of predators provide a fertile terrain for future explorations. Here, we have explored their possible effects without taking into consideration the fact that twothirds of Lizard Island was closed to fishing in 2004. Fitting the model to fish data will allow us to compare a partially closed reef, such as Lizard Island, with fully closed and open reefs. Moreover, the effects of different types of COTS predators (large fish, invertebrates, and small fish preying on adult and/or juve- 
nile COTS) could be investigated both separately and in relation to each other, providing the start for the investigation of trophic cascades. Further, the effect of predators could be assessed under different scenarios of recruitment intensity and/or nutrient loading, whilst adding the spatial component and investigating the effects of reef connectivity and source-sink dynamics which have been identified elsewhere as key components of COTS-coral interactions. Future efforts could concentrate on understanding the interacting roles of coral decline in affecting large fish breeding success versus the impacts of large fish on COTS densities. The introduction of a spatial dimension via the inclusion of more reefs and the use of indices of relative abundance for large fishes at each of the selected reefs in the historical fitted model would enable this analysis. As suggested by McCallum (1989) and Keesing \& Halford (1992b), investigating the effects of densitydependent mortality of COTS and its relevance at different life stages will also be of major importance to achieving a global understanding of the problem. Similarly, it will be important to understand why the observed steep decline in COTS numbers at Lizard Island was more rapid than might be expected from general demographic information.

Thus, future work foresees the inclusion of other key predators (e.g. tritons and small fish) and the role of no-take zones, anthropogenic nutrient enhancement, and reef connectivity in mediating the spatiotemporal heterogeneity of COTS outbreaks, as well as the evaluation of other management tools such as the introduction of diseases and viruses and the use of chemical cues as baiting strategies. The success of these model extensions is largely dependent upon the availability of adequate data series to which to fit the model.

Acknowledgements. Thanks go to 3 anonymous reviewers, Scott Condie, and John Keesing, whose valuable comments contributed towards significantly improving the manuscript. This work was supported by the CSIRO Wealth from Oceans Flagship. We particularly acknowledge the Australian Institute of Marine Science for making the Long Term Monitoring Program data available.

\section{LITERATURE CITED}

Babcock RC (1990) Spawing behaviour of Acanthaster planci. Coral Reefs 9:124

Babcock RC, Mundy CN (1992) Reproductive biology, spawning and field fertilization rates of Acanthaster planci. Mar Freshw Res 43:525-533

Benzie J (1992) Review of the genetics, dispersal and re- cruitment of crown-of-thorns starfish (Acanthaster planci). Mar Freshw Res 43:597-610

Benzie JAH, Stoddart JA (1992) Genetic structure of outbreaking and non-outbreaking crown-of-thorns starfish (Acanthaster planci) populations on the Great Barrier Reef. Mar Biol 112:119-130

Birkeland C (1982) Terrestrial runoff as a cause of outbreaks of Acanthaster planci (Echinodermata: Asteroidea). Mar Biol 69:175-185

Birkeland C, Lucas JS (1990) Acanthaster planci: major management problem of coral reefs. CRC Press, Boca Raton, FL

Blamey LK, Plagányi ÉE, Branch GM (2013) Modeling a regime shift in a kelp forest ecosystem caused by a lobster range expansion. Bull Mar Sci 89:347-375

Bos AR, Gumanao GS, Mueller B, Saceda-Cardoza MME (2013) Management of crown-of-thorns sea star (Acanthaster planci L.) outbreaks: Removal success depends on reef topography and timing within the reproduction cycle. Ocean Coast Manag 71:116-122

Bradbury RH, van der Laan JD, Macdonald B (1990) Modelling the effects of predation and dispersal on the generation of waves of starfish outbreaks. Math Comput Model 13:61-67

Brodie J (1992) Enhancement of larval and juvenile survival and recruitment in Acanthatser planci from the effects of terrestrial runoff: a review. Mar Freshw Res 43:539-553

> Brodie J, Waterhouse J (2012) A critical review of environmental management of the 'not so Great' Barrier Reef. Estuar Coast Shelf Sci 104-105:1-22

> Brodie J, Fabricius K, De'ath G, Okaji K (2005) Are increased nutrient inputs responsible for more outbreaks of crown-of-thorns starfish? An appraisal of the evidence. Mar Pollut Bull 51:266-278

> Chesher RH (1969) Destruction of Pacific corals by the sea star Acanthaster planci. Science 165:280-283

- Dana TF (1970) Acanthaster: a rarity in the past? Science 169:894

De'ath G, Moran PJ (1998a) Factors affecting the behaviour of crown-of-thorns starfish (Acanthaster planci L.) on the Great Barrier Reef. 1. Patterns of activity. J Exp Mar Biol Ecol 220:83-106

> De'ath G, Moran PJ (1998b) Factors affecting the behaviour of crown-of-thorns starfish (Acanthaster planci L.) on the Great Barrier Reef. 2. Feeding preferences. J Exp Mar Biol Ecol 220:107-126

> Dulvy NK, Freckleton RP, Polunin NVC (2004) Coral reef cascades and the indirect effects of predator removal by exploitation. Ecol Lett 7:410-416

> Fabricius K, Okaji K, De'ath G (2010) Three lines of evidence to link outbreaks of the crown-of-thorns seastar Acanthaster planci to the release of larval food limitation. Coral Reefs 29:593-605

Fisk DA, Power MC (1999) Development of cost-effective control strategies for crown-of-thorns starfish. CRC Reef Research Centre, Townsville

> Fournier DA, Skaug HJ, Ancheta J, Ianelli JN and others (2012) AD Model Builder: using automatic differentiation for statistical inference of highly parameterized complex nonlinear models. Optim Methods Softw 27:233-249

Glynn PW (1982) Acanthaster population regulation by a shrimp and a worm. Proc 4th Int Coral Reef Symp 2: 607-612

Henderson RA, Walbran PD (1992) Interpretation of the fossil record of Acanthaster planci from the Great Barrier 
Reef: a reply to criticism. Coral Reefs 11:95-101

Holling CS (1959) The components of predation as revealed by a study of small-mammal predation of the European pine sawfly. Can Entomol 91:293-320

James MK, Dight IJ, Bode A (1990) Great Barrier Reef hydrodynamics, reef connectivity and Acanthaster population dynamics. In: Bradbury RH (ed) Acanthaster and the coral reef: a theoretical perspective. Springer-Verlag, Berlin, p 17-44

> Johnson DB, Moran PJ, Driml S (1990) Evaluation of a crown-of-thorns starfish (Acanthaster planci) control program at Grub Reef (central Great Barrier Reef). Coral Reefs 9:167-171

Keesing JK (1993) The influence of persistent populations of the starfish Acanthaster planci (L.) and the sea urchin Echinometra mathaei on coral reef community structure in Okinawa, Japan. Proc 7th Int Coral Reef Symp 2:769-779

Keesing JK, Halford A (1992a) Importance of postsettlement processes for the population dynamics of Acanthaster planci (L.). Mar Freshw Res 43:635-651

Keesing JK, Halford AR (1992b) Field measurement of survival rates of juvenile Acanthaster planci: techniques and preliminary results. Mar Ecol Prog Ser 85:107-114

Keesing JK, Lucas JS (1992) Field measurement of feeding and movement rates of the crown-of-thorns starfish Acanthaster planci (L.). J Exp Mar Biol Ecol 156:89-104

Keesing JK, Bradbury RH, DeVantier LM, Riddle MJ, De'ath G (1992) Geological evidence for recurring outbreaks of the crown-of-thorns starfish: a reassessment from an ecological perspective. Coral Reefs 11:79-85

Keesing JK, Wiedermeyer WL, Okaji K, Halford AR, Hall KC, Cartwright CM (1995) Mortality rates of juvenile starfish Acanthaster planci and Nardoa spp. measured on the Great Barrier Reef. Oceanol Acta 19:441-448

- Kenchington RA (1977) Growth and recruitment of Acanthaster planci (L.) on the Great Barrier Reef. Biol Conserv 11:103-118

Lassig B, Engelhardt U, Moran PJ, Ayukai T (1995) Review of the Crown-of-Thorns Starfish Research Committee (COTSREC) Program. Research Publication no. 39, Great Barrier Reef Marine Park Authority, Townsville

> Lourey MJ, Ryan DAJ, Miller IR (2000) Rates of decline and recovery of coral cover on reefs impacted by, recovering from and unaffected by crown-of-thorns starfish Acanthaster planci: a regional perspective of the Great Barrier Reef. Mar Ecol Prog Ser 196:179-186

Lucas JS (1973) Reproductive and larval biology of Acanthaster planci (L.) in Great Barrier Reef waters. Micronesica 9:197-203

> Lucas JS (1982) Quantitative studies of feeding and nutrition during larval development of the coral reef asteroid Acanthaster planci (L.). J Exp Mar Biol Ecol 65:173-193

McCallum HI (1987) Predator regulation of Acanthaster planci. J Theor Biol 127:207-220

McCallum HI (1989) Effects of predation on organisms with pelagic larval stages: models of metapopulations. Proc 6th Int Coral Reef Symp 2:101-106

McCallum HI (1990) Effects of predation on Acanthaster: age-structured metapopulation models. In: Bradbury RH (ed) Acanthaster and the coral reef: a theoretical perspective, Springer-Verlag, Berlin, p 208-219

Miller IR, Jonker M, Coleman G (2009) Crown-of-thorns starfish and coral surveys using the manta tow and SCUBA search techniques. Long-term Monitoring of the
Great Barrier Reef Standard Operation Procedure Number 9, Australian Institute of Marine Science, Townsville. www.aims.gov.au/docs/research/monitoring /reef/sops.html

Moran PJ (1986) The Acanthaster phenomenon. Oceanogr Mar Biol Annu Rev 24:379-480

Moran PJ, De'ath G (1992) Estimates of the abundance of the crown-of-thorns starfish Acanthaster planci in outbreaking and non-outbreaking populations on reefs within the Great Barrier Reef. Mar Biol 113:509-515

Ormond RFG, Campbell AC, Head SH, Moore RJ, Rainbow PR, Saunders AP (1973) Formation and breakdown of aggregations of the crown-of-thorns starfish, Acanthaster planci (L.). Nature 246:167-169

Ormond RFG, Bradbury RH, Bainbridge SJ, Fabricius K and others (1990) Test of a model of regulation of crown-ofthorns starfish by fish predators. In: Bradbury RH (ed) Acanthaster and the coral reef: a theoretical perspective. Springer-Verlag, Berlin, p 189-207

Osborne K, Dolman AM, Burgess SC, Johns KA (2011) Disturbance and the dynamics of coral cover on the Great Barrier Reef (1995-2009). PLoS ONE 6:e17516

Pearson TH, Endean R (1969) A preliminary study of the coral predator Acanthaster planci (L.) (Asteroidea) on the Great Barrier Reef. Dep Harb Mar Qld Fish Notes 3: $27-68$

> Plagányi ÉE, Butterworth DS (2010) A spatial- and agestructured assessment model to estimate the impact of illegal fishing and ecosystem change on the South African abalone Haliotis midae resource. Afr J Mar Sci 32:207-236

Plagányi ÉE, Butterworth DS (2012) The Scotia Sea krill fishery and its possible impacts on dependent predators: modeling localized depletion of prey. Ecol Appl 22: 748-761

> Plagányi ÉE, Punt AE, Hillary R, Morello EB and others (2014) Multispecies fisheries management and conservation: tactical applications using models of intermediate complexity. Fish Fish 15:1-22

Pratchett M (2001) Dynamics of outbreak populations of crown-of-thorns starfish (Acanthaster planci L.), and their effects on coral reef ecosystems. PhD James Cook University, Townsville

Pratchett M (2005) Dynamics of an outbreak population of Acanthaster planci at Lizard Island, northern Great Barrier Reef (1995-1999). Coral Reefs 24:453-462

> Pratchett M (2010) Changes in coral assemblages during an outbreak of Acanthaster planci at Lizard Island, northern Great Barrier Reef (1995-1999). Coral Reefs 29: 717-725

Reichelt RE, Bradbury RH, Moran PJ (1990) Distribution of Acanthaster planci outbreaks on the Great Barrier Reef between 1966 and 1989. Coral Reefs 9:97-103

Seymour RM, Bradbury RH (1999) Lengthening reef recovery times from crown-of-thorns outbreaks signal systemic degradation of the Great Barrier Reef. Mar Ecol Prog Ser 176:1-10

> Sweatman HPA (1995) A field study of fish predation on juvenile crown-of-thorns starfish. Coral Reefs 14:47-53

Sweatman H (1997) Commercial fish predators of adult Acanthaster planci. Proc 8th Int Coral Reef Sym 1: $617-620$

Sweatman H (2008) No-take reserves protect coral reefs from predatory starfish. Curr Biol 18:R598-R599

Sweatman H, Cheal AJ, Coleman G, Emslie M and others 
(2008) Long-term monitoring of the Great Barrier Reef. Australian Institute of Marine Sciences, Townsville

Timmers MA, Bird CE, Skillings DJ, Smouse PE, Toonen RJ (2012) There's no place like home: Crown-of-thorns outbreaks in the Central Pacific are regionally derived and independent events. PLoS ONE 7:e31159

van der Laan JD, Bradbury RH (1990) Futures for the Great Barrier Reef ecosystem. Math Comp Model 14:705-709

Weisberg M, Reisman K (2008) The robust Volterra theory. Philos Sci 75:106-131

Submitted: November 7, 2013; Accepted: May 13, 2014
Yamaguchi M (1986) Acanthaster planci infestations of reefs and coral assemblages in Japan: a retrospective analysis of control efforts. Coral Reefs 5:23-30

Zann L, Brodie J, Berryman C, Naqasima M (1987) Recruitment, ecology, growth and behavior of juvenile Acanthaster planci (L.) (Echinodermata: Asteroidea). Bull Mar Sci 41:561-575

Zann L, Brodie J, Vuki V (1990) History and dynamics of the crown-of-thorns starfish Acanthaster planci (L.) in the Suva area, Fiji. Coral Reefs 9:135-144

Proofs received from author(s): August 27, 2014 